\title{
Tracking Changes in Child Welfare: Using Quality Assurance to Monitor Child Welfare Outcomes
}

\author{
By Suzanne Sutphin* \\ Asha Purohit ${ }^{\dagger}$
}

Child welfare and ensuring children are safe from abuse and neglect is critically important. Also of great importance is evaluating the system tasked to protect these children. A large part of this evaluation is done through statewide quality assurance reviews. The reviews are conducted using a federally developed instrument designed to measure outcomes of safety, permanency, and well-being. As part of the review, counties are rated on these outcomes and the data is compiled to examine overall state performance. Many of the social indicators that cause children to come into the state child welfare system affect the items on which the state's cases are rated. This descriptive study attempts to show the potential impact of social indicators associated with potential child abuse and neglect on outcomes of safety and well-being for children involved in the child welfare system.

Keywords: Child welfare, Evaluation, Social indicators, State-level data.

\section{Introduction}

The Child and Family Services Review (CFSR) was developed by the US Department of Health and Human Services. The goal of the reviews is to 1. ensure that states comply with federal child welfare requirements, 2 . examine the outcomes of children and families in the child welfare system, and 3. help states identify areas where they can improve capacity. As part of the CFSR, states are required to periodically review child welfare cases using the Onsite Review Instrument (OSRI). This instrument consists of 23 items that measure 7 outcomes of safety, permanency, and well-being. ${ }^{1}$

There are also societal factors that impact the number of child welfare cases in the counties. Using KIDS COUNT data, a national data collection that assesses a number of social indicators, this paper will explore state-level data on key demographic factors that can potentially affect child welfare outcomes. These social indicators can be used as predictors for children who are at risk of entering care and, for the purposes of this paper, can play a part in the agency's performance on many of the items measured by the OSRI. The following is an

\footnotetext{
${ }^{*}$ Research Assistant Professor, University of South Carolina, USA.

${ }^{\dagger}$ Protection and Advocacy for People with Disabilities, University of South Carolina, USA.

${ }^{1}$ In 2015 the Onsite Review Instrument was revised and condensed to 18 items.
} 
examination of data from KIDS COUNT and the quality assurance reviews to help provide a more accurate picture of how these indicators potentially impact child welfare in one southeastern state.

\section{Literature Review}

A number of social indicators were identified as impacting child welfare and the quality assurance review outcomes. In the section below, we will describe each indicator as it is measured and discuss the potential effects on child welfare.

\section{Social Indicators that Impact Child Abuse and Neglect}

For the purposes of this analysis, we will discuss four social indicators and four sub indicators that have proven to impact child abuse and neglect.

\section{Children in Poverty}

Overall, poverty has been found to be one of the more important indicators of child maltreatment and neglect (Drake and Pandy 1996, Pelton 1978, Sedlak et al. 2010, Slack et al. 2004). In a series of studies conducted by The National Center on Child Abuse and Neglect (1989), poverty was found to be one of the main indicators of a potentially neglecting family. Coulton, Korbin, Su, and Chow (1995) and Gillham, Tanner, Cheyne, Freeman, Rooney and Lambie (1998) also found child poverty to impact risk of child abuse and neglect. Lee and Goerge (1999) found that low income families were more likely to have child maltreatment cases compared to other families. As we will see, children in poverty also affect the other indicators being explored for this analysis. The next three social indicators fall under the larger category of children in poverty.

\section{Median Family (with child) Income}

The median family income for families with children has been demonstrated to have an impact on risk of child abuse and neglect. For example, Gelles (1992) found that low income families were at a great risk of potentially harming their children. This was supported by Berger (2004) whose research indicated that income affects potential risk of child maltreatment such that lower income families are at greater risk for child maltreatment, such as spanking, and other indicators on the maltreatment index. More recently, Slack et al. (2011) found that income can affect the ability for the family to provide meals to the children, which can lead to neglect.

\section{Children under 18 with no Parent in the Labor Force}

Compared to children whose parents are employed, children with unemployed parents can experience up to two to three times higher rates of 
child abuse and neglect (Sedlak 1991, Sedlak and Broadhurst 1996, Sedlak et al. 2010). Aber (2013) found unemployment to be a main factor in potential child maltreatment. The research of Gillham et al. (1998) and Gil (1970) found that male unemployment was correlated with higher rates of child abuse. Millet, Lanier, and Drake (2011) also found rates of child abuse to increase along with rates of unemployment.

\section{Children Living in Areas of Concentrated Poverty}

Many studies have demonstrated the relationship between neighborhood poverty and child abuse and neglect (Coulton et al. 1995, Deccio et al. 1994, Drake and Pandy 1996, Ernst 2001, Freisthler 2004, Freisthler et al. 2004). Maltreatment rates in neighborhoods can be the results of individual level factors, such as stress levels of the parent(s) (Smith and Jarjoura 1989), and neighborhood factors, such as a lack of social resources (Coulton et al. 1999). Drake and Pandy (1996) found types and rates of maltreatment increase with increased poverty in a neighborhood with the strongest link being between poverty and neglect. This is largely attributed to rates of unemployment in a neighborhood (Freisthler 2004, Deccio et al. 1994, Krishnan and Morrison 1995). The percentage unemployed in a neighborhood has also been associated with maltreatment reports (Zuravin 1989). Young and Gately (1988) also found unemployment rates in a neighborhood to be a factor in child maltreatment rates specifically for male perpetrators.

\section{Children living in single parent families}

Dubowitz (1999) found that single-parents with limited resources were at increased risk to maltreat their children. Both Gelles (1992) and Berger (2004) found that single parents were at a higher risk to potentially maltreat their children. In a 17-year prospective study conducted by Brown, Cohen, Johnson, and Salzinger (1998), a child having lived in a single parent household was among demographic risk factors found to be associated with both self-reported and official records of child neglect. Gillham et al. (1998) found that a single measure of ratio of single parents was noted to be correlated with the total abuse rate and the rates for physical and sexual abuse and neglect. More specifically, among the measures studied by Gillham et al. (1998), single parent measures were among the highest correlations to maltreatment.

\section{Live Births to Single Mothers}

Single mothers were found to have a great effect on whether or not a child was likely to experience maltreatment (Coulton et al. 1995). Gelles (1992) found that children living with single mothers were at greater risk of harm. In a study conducted by Berger (2004), children in single-mother families were most likely to have increased spankings (four or more times) by their mothers in a week. This research also found that children in single mother families whose mothers worked outside of the home were at a greater risk of abuse 
(Berger 2004). On the maltreatment index, children living in single mother families did more poorly on three of the five maltreatment indicators compared to children in traditional two-parent families.

\section{Live births to mothers under 18}

There has been contradictory information around maternal age as a predictor of maltreatment. There has been a great amount of research indicating the risk of harm to children born to young mothers (Bolton et al. 1980, DePaul and Domenech 2000, Gelles 1992, Mackenzie et al. 2011, Slack et al. 2004, Strathearn et al. 2009). Lee and Goerge (1999) found maternal age to be a single predictor of risk of child maltreatment, which was intensified when the mother also lives in a high poverty area.

Other studies have not found a relationship between mother's age at birth and likeliness to maltreat (Massat 1995). These studies have found that other confounding factors such as family size, education and employment influence the effect (Zuravin 1988). Yet another study found that age combined with stress, lack of social support, and lack of family organization can lead to potential maltreatment (Miller 1984). This cumulative impact is supported by Mackenzie et al. (2011) who found that age in combination with receiving social services, income, and the safety of the neighborhood impact potential maltreatment.

Live births to mothers with less than a high school education

In a 1989 study conducted by The National Center for Child Abuse and Neglect, education level of the caregivers was found to be different in families who had cases of neglect and those who did not. Parent's level of education was also found to be linked to child maltreatment of infants and early childhood abuse and neglect (Brayden et al. 1992, Hunter et al. 1978, Kotch et al. 1995, Kotch et al. 1999, Slack et al. 2004, Strathearn, et al. 2009, Wu et al. 2004). In these studies, lower levels of education were associated with increased risk of maltreatment.

\section{Quality Assurance Reviews}

The southeastern state in the analysis currently uses the quality assurance review process as a means to continually monitor and improve child welfare practice and assess compliance with state and federal policy.

\section{History}

In 1994, an Amendment to the Social Security Act authorized the U.S. Department of Health and Human Services to conduct Child and Family Services Reviews (CFSRs) of child welfare programs in order to ensure conformity to policy and procedure on key outcomes. The first review completed by all 50 states and the District of Columbia and Puerto Rico occurred in 2004 and have since continued. The ultimate goal of the CFSR is to 
assist states in enhancing their capacity to help children and families involved in the child welfare system achieve positive outcomes.

In addition to the federally mandated CFSRs, this southeastern state has implemented a more rigorous quality assurance review process and has been committed to reviewing counties more frequently than the once per five year requirement. This allowed the state to track changes in policy and procedure over time with the goal of improving outcomes for children in the state.

\section{Types of cases reviewed}

The quality assurance reviews examine both foster care and family preservation cases. Foster care is defined as the "24-hour substitute care for children placed away from their parents or guardians and for whom the State agency has placement and care responsibility. This includes, but is not limited to, placements in foster family homes, foster homes of relatives, group homes, emergency shelters, residential facilities, child care institutions, and preadoptive homes," (US DHHS 2000). Family preservation is defined as "services for children and families designed to help families (including adoptive and extended families) at risk or in crisis" and may take place with the child remaining in the home or with family members (US DHHS 2000).

\section{The onsite review instrument (OSRI)}

The quality assurance reviews use the CFSR's Onsite Review Instrument (OSRI). The OSRI is divided into three sections: safety, permanency, and wellbeing. There are two safety outcomes, two permanency outcomes, and three well-being outcomes. Cases are reviewed based on a one year period under review prior to the date of review. Foster care cases are rated on all 23 items and 7 outcomes, while family preservation cases are only rated on safety and well-being outcomes, consisting of 11 items. In the OSRI, the items are rated as strength, area needing improvement, or not applicable. The ratings for each item are combined to determine the overall rating for the outcome. Outcomes are rated as being substantially achieved, partially achieved, not achieved, or not applicable.

\section{Quality assurance review process}

Before each review, the foster care and family preservation cases are randomly selected for review from the overall universe of eligible cases based on certain standardized review criteria. During the review week, a team of trained reviewers use the OSRI to assess the cases according to the rating system described above. Reviewers use information from case files, the agency's online child welfare database, and case related interviews to collect information to rate all applicable items related to each of the outcomes. Each item is given a rating and an explanation as to the information that lead to that rating. This results in quantitative and qualitative information for each case. At the end of each review, researchers at a university analyze the qualitative and quantitative data and produce a report to provide feedback to the counties about their performance in the review and areas needing improvement. 


\section{Methods}

The goal of this research was to use social indicators and sub indicators and data from the quality assurance reviews to draw conclusions regarding the potential impact of the indicators on the outcomes of children in the child welfare system.

\section{Data Sources}

Several data sources were used for this analysis: quality assurance review data, KIDS COUNT, and the United States Census. This allows us to examine how the state rates on the social indicators and performs on the CFSR items.

\section{Quality assurance review data}

Results for outcomes and items are reported by the number of cases reviewed and the percentage of total cases with each rating. In addition, the percentage of strengths is calculated for each item. This percentage is calculated by adding the number of strengths and the number of areas needing improvement. The number of strengths is divided into this total to determine the percentage of strengths. For this analysis, however, we were focused on the percentage of areas needing improvement (ANI) for each item. To determine this number we subtracted the percentage of strengths from 100 to get the percentage of ANIs.

\section{KIDS COUNT data}

To obtain data for the social indicators, we used Annie E. Casey's KIDS COUNT Data Center. KIDS COUNT seeks to monitor the well-being of children in the United States. The data collected in and provided by KIDS COUNT is obtained from over 50 KIDS COUNT state organizations and, through the national project, reports are developed and distributed by the Foundation. The data in this state is collected by a single statewide organization. The foundation produces an annual KIDS COUNT Data Book as well as maintains an online Data Center (Annie E. Casey 2015a).

The children in poverty indicator is included in the Economic Well-Being sections of KIDS COUNT data. The poverty status of families is defined using income cutoffs from the Census Bureau as well as other classifiers, taking family size into consideration. Information sources for calculating this indicator were the U.S. Census Bureau, Small Area Income and Poverty Estimates (Annie E. Casey 2015b).

Median family (with child) income indicator also comes from the Economic Well-Being in the Income and Employment section. The calculations are made by examining income distribution. Families fall either below or above the median income. Data used for calculation comes from the U.S. Census Bureau and 5 year estimates from the American Community Survey (Annie E. Casey 2015h). 
For children under 18 with no parent in the labor force, Annie E. Casey used data from the U.S. Census Bureau and the American Community Survey to calculate the percent of children below the age of 18 with parents not in the labor force. The data source for this indicator was the U.S. Census Bureau and the American Community Survey (Annie E. Casey 2015d).

The children living in areas of concentrated poverty indicator represents those children who live in census tracts where the poverty rate is greater than or equal to $30 \%$. The calculation used data from the Population Reference Bureau's analysis of U.S. Census Bureau data (Annie E. Casey 2014).

The live births to single parents indicator is defined using marital status on the birth certificate. The data source for this indicator was the state's Department of Health and Environmental Control (Anne E. Casey 2015c).

The live births to mothers under 18 indicator uses birth certificate data to calculate the percent of mothers who were under the age of 18 when they gave birth. This was calculated using data from the state's Department of Health and Environmental Control (Annie E. Casey 2015e).

Live births to single mothers, paternity acknowledged, is defined through the use of marital status on the birth certificate. The data source for this indicator was the state's Department of Health and Environmental Control (Annie E. Casey 2015g).

Live births to mothers with less than a high school education indicator accounts for women who delivered prior to completion of the twelfth grade. Data for this indicator came from the state's Department of Health and Environmental Control (Annie E. Casey 2015f).

Quality assurance and social indicators

Table 1 shows how the social indicators and sub indicators described can impact certain items of interest on the CFSR. For the purposes of this analysis, we are focused on Safety Outcome 2 and Well-being Outcomes 1 and 3. The other items and outcomes are included in the table for informational purposes but put in grey to show their exclusion.

\section{Demographic data}

For the demographic data, we used the United States Census Bureau (2015) for population information, the state's Department of Social Services (2012) data for information about individuals receiving supplemental nutrition assistance program (SNAP) benefits, and the United States Department of Agriculture Food and Nutrition Service (2015) data for national SNAP numbers.

Table 2 provides key demographic information for the southeastern state compared to the national data. In all of the social indicators provided in Table 2 , this state rates above the national average. Overall, the state has particularly high rates of children living in single parent families and live births to single mothers. 
Table 1. CFSR Items and Related Social Indicators

\begin{tabular}{|c|c|}
\hline \multirow{2}{*}{\multicolumn{2}{|c|}{ Safety Outcome 1: Children are, first and foremost, protected from abuse and neglect. }} \\
\hline & \\
\hline \multicolumn{2}{|l|}{ Item 1: Timeliness to initiate investigations } \\
\hline \multirow{2}{*}{\multicolumn{2}{|c|}{$\begin{array}{l}\text { Item 2: Repeat maltreatment } \\
\text { Safety Outcome 2: Children are safely maintained in their homes whenever possible and } \\
\text { appropriate }\end{array}$}} \\
\hline & \\
\hline Item 3: Services to family & $\begin{array}{l}\text { Children in poverty (2012) } \\
\text { Children under } 18 \text { with no parent in the labor } \\
\text { force (2009-13) } \\
\text { Children living in areas of concentrated } \\
\text { poverty (2009-13) } \\
\text { Children living in single parent families } \\
\text { (2009-13) }\end{array}$ \\
\hline $\begin{array}{l}\text { Item 4: Risk assessment and safety } \\
\text { management }\end{array}$ & $\begin{array}{l}\text { Children in poverty (2012) } \\
\text { Children under } 18 \text { with no parent in the labor } \\
\text { force (2009-13) } \\
\text { Children living in areas of concentrated } \\
\text { poverty (2009-13) } \\
\text { Live births to mothers under } 18 \text { (2012) } \\
\text { Live births to mothers with less than a high } \\
\text { school education (2012) }\end{array}$ \\
\hline \multicolumn{2}{|c|}{ Permanency Outcome 1: Children have permanency and stability in their living situations } \\
\hline \multicolumn{2}{|c|}{ Item 5: Foster care reentries } \\
\hline \multicolumn{2}{|l|}{ Item 6: Stability of foster care placement } \\
\hline \multicolumn{2}{|l|}{ Item 7: Permanency goal for child } \\
\hline \multicolumn{2}{|l|}{$\begin{array}{l}\text { Item 8: Reunification, guardianship or } \\
\text { permanent placement with relatives }\end{array}$} \\
\hline \multicolumn{2}{|l|}{ Item 9: Adoption } \\
\hline \multicolumn{2}{|l|}{ Item 10: Other Planned Living Arrangement } \\
\hline \multicolumn{2}{|c|}{$\begin{array}{l}\text { Permanency Outcome 2: The continuity of family relationships and connections is } \\
\text { preserved for children }\end{array}$} \\
\hline \multicolumn{2}{|l|}{ Item 11: Proximity of foster care placement } \\
\hline \multicolumn{2}{|l|}{ Item 12: Placement with siblings } \\
\hline \multicolumn{2}{|l|}{$\begin{array}{l}\text { Item 13: Visits with parents and siblings in } \\
\text { foster care }\end{array}$} \\
\hline \multicolumn{2}{|l|}{ Item 14: Preserving connections } \\
\hline \multicolumn{2}{|l|}{ Item 15: Relative placement } \\
\hline \multicolumn{2}{|l|}{$\begin{array}{l}\text { Item 16: Relationship of child in care with } \\
\text { parents }\end{array}$} \\
\hline \multicolumn{2}{|c|}{ Well-being Outcome 1: Families have enhanced capacity to provide for their children's needs } \\
\hline $\begin{array}{l}\text { Item 17: Needs and services of child, parents, } \\
\& \text { foster parents }\end{array}$ & $\begin{array}{l}\text { Children in poverty (2012) } \\
\text { Children under } 18 \text { with no parent in the labor } \\
\text { force (2009-13) } \\
\text { Children living in areas of concentrated } \\
\text { poverty (2009-13) } \\
\text { Children living in single parent families } \\
\text { (2009-13) } \\
\text { Live births to single mothers (includes } \\
\text { paternity acknowledged) (2012) } \\
\text { Live births to mothers under } 18 \text { (2012) } \\
\text { Live births to mothers with less than a high } \\
\text { school education (2012) }\end{array}$ \\
\hline Item 18: Child \& fo & Children living in single parent families \\
\hline
\end{tabular}




\begin{tabular}{|c|c|}
\hline planning & $\begin{array}{l}\text { (2009-13) } \\
\text { Live births to single mothers (includes } \\
\text { paternity acknowledged) (2012) } \\
\text { Live births to mothers under } 18 \text { (2012) } \\
\text { Live births to mothers with less than a high } \\
\text { school education (2012) }\end{array}$ \\
\hline \multicolumn{2}{|l|}{ Item 19: Caseworker visits with child } \\
\hline Item 20: Caseworker visits with parents & $\begin{array}{l}\text { Children living in single parent families } \\
\text { (2009-13) } \\
\text { Live births to single mothers (includes } \\
\text { paternity acknowledged) (2012) } \\
\text { Live births to mothers under } 18 \text { (2012) } \\
\text { Live births to mothers with less than a high } \\
\text { school education (2012) }\end{array}$ \\
\hline \multicolumn{2}{|c|}{ Well-being Outcome 2: Children receive appropriate services to meet their educational needs } \\
\hline Item 21: Educational needs of child & \\
\hline \multicolumn{2}{|c|}{$\begin{array}{l}\text { Well-being Outcome 3: Children receive adequate services to meet their physical and } \\
\text { mental health needs }\end{array}$} \\
\hline Item 22: Physical health of child & $\begin{array}{l}\text { Children in poverty (2012) } \\
\text { Children under } 18 \text { with no parent in the labor } \\
\text { force (2009-13) } \\
\text { Children living in areas of concentrated } \\
\text { poverty (2009-13) }\end{array}$ \\
\hline Item 23: Mental/behavioral health of child & $\begin{array}{l}\text { Children in poverty (2012) } \\
\text { Children under } 18 \text { with no parent in the labor } \\
\text { force (2009-13) } \\
\text { Children living in areas of concentrated } \\
\text { poverty (2009-13) }\end{array}$ \\
\hline
\end{tabular}

Note: Items in grey are not included in the analysis.

Source: KIDS COUNT and US Census.

Table 2. State and National Demographic Data

\begin{tabular}{|l|l|l|}
\hline \multicolumn{2}{|l|}{ State } & Nation \\
\hline Population & $4,625,364$ & $315,255,012$ \\
\hline $\begin{array}{l}\text { Receiving Supplemental Nutrition Assistance } \\
\text { Program Benefits }\end{array}$ & $23 \%$ & $15 \%$ \\
\hline $\begin{array}{l}\text { Total number of founded investigations of Child } \\
\text { Abuse/Neglect (2012) }\end{array}$ & 5,800 & 596,722 \\
\hline & State & Nation \\
\hline Child Poverty Indicators & & $\$ 59,500$ \\
\hline Median family (with child) income (2009-13) & $\$ 50,967$ & $23 \%$ \\
\hline Children in Poverty (2012) & $26.8 \%$ & $6 \%$ \\
\hline $\begin{array}{l}\text { Children under 18 with no parent in the labor } \\
\text { force (2009-13) }\end{array}$ & $9.2 \%$ & $14 \%$ \\
\hline $\begin{array}{l}\text { Children living in areas of concentrated poverty } \\
\text { (2009-13) }\end{array}$ & $15 \%$ & $35 \%$ \\
\hline $\begin{array}{l}\text { Children living in single parent families (2009- } \\
13 \text { ) }\end{array}$ & $41.4 \%$ & $41 \%$ \\
\hline $\begin{array}{l}\text { Live births to single mothers (includes paternity } \\
\text { acknowledged) (2012) }\end{array}$ & $47.8 \%$ & $2.3 \%$ \\
\hline Live births to mothers under 18 (2012) & $2.7 \%$ & $17 \%$ \\
\hline $\begin{array}{l}\text { Live births to mothers with less than a high } \\
\text { school education (2012) }\end{array}$ & $18.2 \%$ & \\
\hline Source: KIDS COUNT ans Censis. & & \\
\hline
\end{tabular}

Source: KIDS COUNT and US Census. 


\section{Results}

In looking at the results, we are focused on Safety Outcome 2 and Wellbeing Outcomes 1 and 3 for the 2013 calendar year. For comparison purposes, we used the 2013 reviews as the period under review, which is one year prior to the review date, provided data that aligned most closely with the other statistics presented for the social indicators. Below we describe each item, how it is rated, and the common trends observed that lead to the rating of ANI for that particular item.

\section{Safety Outcome 2}

Safety Outcome 2 measures Item 3 and 4 that assess whether or not children can be maintained safely in their homes. The items determine the agency's efforts to provide services to children and families in order to prevent entry, or reentry following reunification, into care. Additionally, this outcome focuses on the ability of the agency to appropriately assess risk and manage a child's safety, whether in their own home or in a foster care placement.

$\underline{\text { Item } 3}$

Item 3 examines the services that are provided to the family that can potentially prevent removal of the child or re-entry into foster care if the child had been reunified with his/her parent(s). To identify needed services, caseworkers must complete a safety assessment to determine that the home is safe for the child and ensure that the family is able to access the identified services. These services can include, for example, substance abuse treatment and anger management classes for the parents and mental health or educationrelated services for the child(ren).

This state had a 38.4\% Area Needing Improvement rating on this item. Trends that are seen with Item 3 that lead to ANI ratings include failure to conduct all adequate and appropriate assessments and using these assessments to arrange for the provision of services that meet the needs of the children and family working with the agency.

\section{Item 4}

Item 4 focuses on risk assessment and safety management to determine if safety concerns related to the children and their home or foster care placement were addressed. Caseworkers should conduct ongoing risk assessments and identify any concerns. Safety plans should then be developed to address those concerns and should be monitored and updated by the caseworker.

This state had a $37.8 \%$ ANI rating on applicable cases. Cases were largely rated as ANI for this item due to the failure to provide effective risk and safety assessments for children on an ongoing basis. Additionally, all individuals living in the home may not have been seen face-to-face for an assessment, a factor which would result in an ANI rating. Further, in this item there is also a trend of failure by the agency to seek court intervention when parents were not 
engaging in services, failure to address known safety concerns, and failure to complete all documentation necessary such as safety plans, alternative caregiver documentation, and home visit guides.

\section{Results for Safety Outcome 2}

Based on the literature reviewed, there are several social indicators that would impact these items for the state. Children in poverty, children living in areas of concentrated poverty, and median family (with child) income are the main social indicators that would impact Items 3 and 4. In this state, almost $27 \%$ of the children are living in poverty and $15 \%$ of all children live in areas of concentrated poverty.

High percentages on these indicators affect Items 3 and 4 by potentially making it challenging to arrange services, provide assessments, and complete diligent searches for missing parents. Both Items 3 and 4 require face-to-face visits with children, parents, and others involved in their care. As such many children living in poverty often do not have access to stable housing making these requirements difficult. It is also hard to establish a safety plan for the child with a lack of stable housing and/or living in an impoverished neighborhood.

As noted in the literature review, other social indicators impacting these items including children in single parent families, live births to single mothers, and live births to mothers with less than a high school education, are correlated with out poverty indicators and therefore potentially impact these outcomes. For example, it could be challenging for a single mother to participate in services without adequate childcare. Also, it can be hard for families in isolated areas to have access to transportation to gain access to needed services provided they are available in their area.

\section{Well-being Outcome 1}

Well-being 1 focuses on the capacity families have to provide for their children's needs. This outcome measure Items $17-20$ of which Items 17, 18, and 20 have high percentages of ANI ratings. In order to assess whether families have an enhanced capacity to provide for their children's needs, items in this outcome examine the assessment of needs and provision of services to children, their parents, and foster parents, the involvement of all appropriate family members in case planning, and the visits conducted by the caseworker with parents.

\section{Item 17}

Item 17 measures whether or not the agency provided for the needs and services of the child(ren) in care, their parents, and foster parents (if applicable). This item determines if the agency assessed for and identified needed services to achieve the case goals and provided the appropriate services for the children, parents, and foster parents. 
For this item, $48.1 \%$ of the cases rated as an ANI. Most of the issues identified in Item 17 stem from assessments and services. The issue often lies in assessments and provision of services to parents, not children and foster parents. In cases with an ANI rating, services may not be timely or appropriate, and the agency often failed to ensure that there was engagement in services or sought court intervention when parents were non-compliant with services described in a treatment plan. Issues with assessments included a lack of initial and/or ongoing assessments.

$\underline{\text { Item } 18}$

Item 18 measures whether or not the agency involved the child and family in the case planning process. This includes involving age appropriate children and parents in identifying their strengths, needs, and needed services. They should also develop goals for the case plan and the caseworker should continually evaluate their progress during case planning meetings.

For Item 18, $44.2 \%$ of applicable cases were rated as an ANI. Most often, cases received an ANI rating because the agency failed to engage parents in case planning.

Item 20

Item 20 involves caseworker visits with the parents. This includes having visits that are of sufficient frequency and quality to address the safety, permanency, and well-being of the child and to achieve the identified case goals. Concerted efforts to involve both the mother and the father must be demonstrated unless otherwise noted. These visits should include face-to-face contact between the parent(s) and the caseworker.

For Item 20,66.6\% of the applicable cases were rated as an ANI for the state. This is the highest ANI rating for all of the items. The frequency of visits with parents is the primary issue. If there is no visitation occurring, thus impacting frequency, there is therefore not a capacity to assess quality. This issue of frequency can be linked to the failure to conduct diligent searches for missing parents, an issue which can also impact Items 3, 4, 17, and 18. If parents do not have contact with the agency, or contact is lost at some point during the life of the case, required frequency cannot be met.

\section{Results for Well-being Outcome 1}

The social indicators that greatly impact these items are children in single parent families and live births to single mothers. Items 17, 18 and 20 address services to children and parents, case planning, and caseworker visits with parents. Part of rating these items include ensuring that diligent searches are conducted for missing parents. Diligent searches involve making concerted efforts to locate all pertinent adults who should be involved in the case, particularly fathers. This is often a challenge for single parent families especially single mother families where the father is not accessible. Also, in areas of concentrated poverty, it would be challenging to identify needed 
services for parents and to ensure that they are completing the required services when the parents may face potential barriers such as a lack of transportation and a lack of child care.

\section{Well-being Outcome 3}

Well-being Outcome 3 is designed to ensure that children receive adequate services to meet their physical and mental health needs. This outcome includes Items 22 and 23. The rating of this outcome takes into account both the physical and mental/behavioral health needs of children. Therefore, items used to rate this outcome examine the agency's provision of appropriate medical care, to include dental, the provision of appropriate assessment, and whether or not indicated follow-up occurred as well as the maintenance of the children's records within their case file.

\section{Item 22}

Item 22 focuses on the physical health needs of the child, including dental health if age appropriate. Children's health and dental care needs should be assessed and the appropriate services should be provided.

For Item 22, $41.8 \%$ of applicable cases were rated as ANI. Although physical health needs of children may be met, there is a trend of a failure to include all pertinent records (both dental and medical) in the case file, which can result in an ANI rating. Cases often receive an ANI rating because there is a failure to make collateral contact with the different service providers.

\section{Item 23}

Item 23 measures the mental and behavioral health of the child including conducting an assessment upon entry into care and on an on-going basis to be included in the case planning process. Needed services should be identified with the appropriate referrals made to address those needs.

On this item, 29.3\% of applicable cases were rated as ANI. As in Item 22, a common issue resulting in a rating of ANI is the failure to include all appropriate records in the case file or to make collateral contact with the mental/behavioral health provider for the child. Sometimes, there are issue with the provision of timely and appropriate services to all relevant children in the case, which can be especially impactful in managing mental/behavioral health.

\section{Results for Well-being Outcome 3}

The social indicators that have a large impact on these items are median family income, children living in poverty, children in concentrated areas of poverty, and no parent in the labor force. Items 22 and 23 address services to children as it relates to their health. Ensuring the health needs of children are met takes into account physical, dental, mental, and behavioral health. The main parts of rating these items includes both the provision of services related to health as well as ensuring that documentation for these services is included 
in the child's case file. Medical records ensure the continuity of accurate and appropriate care for children and, thus, their inclusion in the case file is integral. Furthermore, it is important to consider the mental/behavioral health of children involved in child welfare as there are possibilities of experienced trauma from abuse, neglect, and/or what they have seen in their home.

The median family income and children living in poverty and areas of concentrated poverty impact these items because these social indicators have the potential to impact both the services that are available in their area as well as the family's financial ability to access services if they are available. The impact of no parent in the labor force as a social indicator related to this items flows logically from the other indicators related to poverty. Additionally, it is important to consider that many individuals may access health insurance through their workplace, and lacking a parent in the labor force can further impact their ability to access and pay for services.

\section{Discussion and Conclusion}

This data begins to show the relationship between social indicators in a state and outcomes of safety and well-being for children in the child welfare system. These outcomes are impacted by more than state and federal child welfare policies and casework practice. They are impacted by many social variables for the children, parents, and communities involved. As discussed, this state is above the national average for all of the social indicators included. Using the data from the quality assurance reviews, the links between these indicators and items on which the state needs to improve offer a better picture of the state of child welfare. It is not simply casework practice or implementing policies. The social indicators in a state affect how those policies are implemented and how the caseworkers are able to complete all of the requirements for a successful case review.

All eight of the social indicators discussed can significantly impact the potential entry into care due to child maltreatment and impact the outcomes for children and families involved in the child welfare system. By focusing on these eight indicators, we see how overarching issues with poverty not only impact potential child abuse and neglect but can significantly impact services. In areas of concentrated poverty, there are a limited number of services available for families and often a lack of access to services. The other social indicators focused on family structure and parent's level of education are correlated with the poverty indicators and access to services. As indicated by Coulton, Korbin, and Su (1999), areas of concentrated poverty and single parent families typically do not have access to social services.

Aggregate assessments of the reviews reveal many systemic issues within the agency including the need for more staff and high caseloads for current caseworkers. Through examining this information regarding social indicators and child welfare outcomes, it could be hypothesized that management of social indicators could lead to a lower rate of children entering care. Fewer 
children entering care would lead to lower caseloads, which could positively affect casework practice. Focusing on the social indicators that cause children to enter care and impact their experiences while in care result in better outcomes for those children and families who are a part of the child welfare system.

\section{References}

Aber J (2013) Poverty, violence, and child development: Untangling family and community level effects. In Threats to optimal development: Integrating biological, psychological, and social risk factors 27, 229-272. Hillsdale, NJ: Psychology Press.

Annie E Casey Foundation (2014) Kids count data center: Children living in areas of concentrated poverty. Retrieved from http://bit.ly/1YWePRJ.

Annie E Casey Foundation (2015a) Kids count data center: About. Retrieved from http://bit.ly/1HSnu3v.

Annie E Casey Foundation (2015b) Kids count data center: Children in Poverty. Retrieved from http://bit.ly/1XS3KE5.

Annie E. Casey Foundation (2015c) Kids count data center: Children living in single parent families (American community survey series). Retrieved from http://bit.ly/1XS406c.

Annie E Casey Foundation (2015d) Kids count data center: Children under 18 with no parent in the labor force. Retrieved from http://bit.ly/1TXrS2x.

Annie E Casey Foundation (2015e) Kids count data center: Live births to mothers under 18. Retrieved http://bit.ly/1NTbLnM.

Annie E Casey Foundation (2015f) Kids count data center: Live births to mothers with less than a high school education. Retrieved from http://bit.ly/1XS4lpj.

Annie E. Casey Foundation (2015g) Kids count data center: Live births to single mothers (includes paternity acknowledged). Retrieved from http://bit.ly/1N95Nvr.

Annie E Casey Foundation (2015h) Kids count data center: Median family (with child) income. Retrieved from http://bit.ly/1XS4AAP.

Berger LM (2004) Income, family structure, and child maltreatment risk. Children and Youth Services Review 26(8): 725-748.

Bolton Jr FG, Laner RH, Kane SP (1980) Child maltreatment risk among adolescent mothers: a study of reported cases. American Journal of Orthopsychiatry 50(3): 489.

Brayden RM, Altemeier WA, Tucker DD, Dietrich MS, Vietze P(1992) Antecedents of child neglect in the first two years of life. The Journal of pediatrics 120(3): 426-429.

Brown J, Cohen P, Johnson JG, Salzinger S (1998) A longitudinal analysis of risk factors for child maltreatment: Findings of a 17-year prospective study of officially recorded and self-reported child abuse and neglect. Child Abuse \& Neglect 22(11): 1065-1078.

Coulton CJ, Korbin JE, Su M (1999) Neighborhoods and child maltreatment: a multilevel study. Child abuse \& neglect 23(11): 1019-1040.

Coulton CJ, Korbin JE, Su M, Chow J (1995) Community level factors and child maltreatment rates. Child development 66(5): 1262-1276. 
Deccio G, Horner WC, Wilson D (1994) High-risk neighborhoods and high-risk families: Replication research related to the human ecology of child maltreatment. Journal of Social Service Research 18(3-4): 123-137.

De Paul J, Domenech L (2000) Childhood history of abuse and child abuse potential in adolescent mothers: A longitudinal study. Child Abuse \& Neglect 24(5): 701713.

Drake B, Pandy S (1996) Understanding the relationship between neighborhood poverty and specific types of child maltreatment. Child Abuse \& Neglect 20(11): 1003-1018.

Dubowitz H (1999) The families of neglected children. In Parenting and child development in nontraditional families, 327-345. New York, NY: Psychology Press.

Ernst JS (2001) Community-level factors and child maltreatment in a suburban county. Social Work Research 25(3): 133-142.

Freisthler B (2004) A spatial analysis of social disorganization, alcohol access, and rates of child maltreatment in neighborhoods. Children and Youth Services Review 26(9): 307-319.

Freisthler B, Midanik LT, Gruenewald PJ (2004) Alcohol outlets and child physical abuse and neglect: applying routine activities theory to the study of child maltreatment. Journal of Studies on Alcohol and Drugs 65(5): 586-592.

Gelles R (1992) Poverty and violence toward children. American Behavioral Scientist 35(3): 258-274.

Gil DG (1970) Violence against children: Physical child abuse in the United States. Cambridge, MA: Harvard University Press.

Gillham B, Tanner G, Cheyne B, Freeman I, Rooney M, Lambie A (1998) Unemployment rates, single parent density, and indices of child poverty: Their relationship to different categories of child abuse and neglect. Child Abuse \& Neglect 22(2): 79-90.

Hunter RS, Kilstrom N, Kraybill EN, Loda F (1978) Antecedents of child abuse and neglect in premature infants: A prospective study in a newborn intensive care unit. Pediatrics 61(4): 629-635.

Kotch JB, Browne DC, Dufort V, Winsor J, Catellier D (1999) Predicting child maltreatment in the first 4 years of life from characteristics assessed in the neonatal period. Child Abuse \& Neglect 23(4): 305-319.

Kotch JB, Browne DC, Ringwalt CL, Stewart PW, Ruina E, Holt K, Lowman B, Jung JW (1995) Risk of child abuse or neglect in a cohort of low-income children. Child Abuse \& Neglect 19(9): 1115-1130.

Krishnan V, Morrison KB (1995) An ecological model of child maltreatment in a Canadian province. Child Abuse \& Neglect 19(1): 101-113.

Lee BJ, Goerge RM (1999) Poverty, early childbearing, and child maltreatment: A multinomial analysis. Children and Youth Services Review 21(9): 755-780.

MacKenzie MJ, Kotch JB, Lee LC (2011) Toward a cumulative ecological risk model for the etiology of child maltreatment. Children and Youth Services Review 33(9): 1638-1647.

Massat CR (1995) Is older better? Adolescent parenthood and maltreatment. Child Welfare: Journal of Policy, Practice, and Program 75(2): 325-335.

Miller SH (1984) The relationship between adolescent childbearing and child maltreatment. Child Welfare: Journal of Policy, Practice, and Program 63(6): 553-557. 
Millet L, Lanier P, Drake B (2011) Are economic trends associated with child maltreatment? Preliminary results from the recent recession using state level data. Children and Youth Services Review 33(7): 1280-1287.

National Center on Child Abuse and Neglect, Department of Health and Human Services (1989) National Center on Child Abuse and Neglect Research Symposium on Child Neglect. February 23-25, 1988. Washington, DC: National Center on Child Abuse and Neglect (DHHS).

Pelton LH (1978) Child abuse and neglect: The myth of classlessness. American Journal of Orthopsychiatry 48(4): 608-617.

Sedlak A (1991) National Incidence and Prevalence of Child Abuse and Neglect, 1988: Revised Report. National Center on Child Abuse and Neglect.

Sedlak AJ, Broadhurst DD (1996) The national incidence study of child abuse and neglect. Washington DC: US Department of Health and Human Services.

Sedlak AJ, Mettenburg J, Basena M, Peta I, McPherson K, Greene A (2010) Fourth national incidence study of child abuse and neglect (NIS-4). Washington, DC: US Department of Health and Human Services.

Slack KS, Berger LM, DuMont K, Yang MY, Kim B, Ehrhard-Dietzel S, Holl JL (2011) Risk and protective factors for child neglect during early childhood: a cross-study comparison. Children and Youth Services Review 33(8): 1354-1363.

Slack KS, Holl JL, McDaniel M, Yoo J, Bolger K (2004) Understanding the risks of child neglect: an exploration of poverty and parenting characteristics. Child Maltreatment 9(4): 395-408.

Smith DA, Jarjoura GR (1989) Household characteristics, neighborhood composition and victimization risk. Social Forces 68(2): 621-640.

South Carolina Department of Social Services (2012) SNAP participation: December 2012. Report FR388. Columbia, South Carolina: Division of Information Systems.

Strathearn L, Mamun AA, Najman JM, O'Callaghan MJ (2009) Does breastfeeding protect against substantiated child abuse and neglect? a 15-year cohort study. Pediatrics 123(2): 483-493.

United States Census Bureau (2015) State \& county Quickfacts: South Carolina. Retrieved from http://1.usa.gov/1NDrvcg.

United States Department of Agriculture Food and Nutrition Service (2015) Retrieved from http://1.usa.gov/110tCJj.

United States Department of Health and Human Services (2000) Code of federal regulations: Federal definition of foster care and related terms. DHHS Publication No. 45CFR1355.20. Washington, DC: US Government Printing Office.

Wu SS, Ma CX, Carter RL, Ariet M, Feaver EA, Resnick MB, Roth J (2004) Risk factors for infant maltreatment: a population-based study. Child Abuse \& Neglect 28(12): 1253-1264.

Young G, Gately T (1988) Neighborhood Impoverishment and Child Maltreatment: an Analysis from the Ecological Perspective. Journal of Family Issues 9(2): 240254.

Zuravin SJ (1988) Child maltreatment and teenage first births: a relationship mediated by chronic sociodemographic stress? American Journal of Orthopsychiatry 58(1): 91-103.

Zuravin SJ (1989) The ecology of child abuse and neglect: Review of the literature and presentation of data. Violence and victims 4:101-120. 